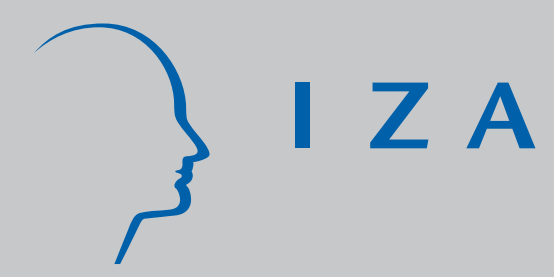

IZA DP No. 3687

Labor Market Policy Evaluation in Equilibrium:

Some Lessons of the J ob Search and Matching Model

Pierre Cahuc

Thomas Le Barbanchon

September 2008 


\title{
Labor Market Policy Evaluation in Equilibrium: Some Lessons of the Job Search and Matching Model
}

\author{
Pierre Cahuc \\ Ecole Polytechnique, CREST, CEPR \\ and IZA \\ Thomas Le Barbanchon \\ DARES and CREST
}

Discussion Paper No. 3687

September 2008

\author{
IZA \\ P.O. Box 7240 \\ 53072 Bonn \\ Germany \\ Phone: +49-228-3894-0 \\ Fax: +49-228-3894-180 \\ E-mail: iza@iza.org
}

\begin{abstract}
Any opinions expressed here are those of the author(s) and not those of IZA. Research published in this series may include views on policy, but the institute itself takes no institutional policy positions.

The Institute for the Study of Labor (IZA) in Bonn is a local and virtual international research center and a place of communication between science, politics and business. IZA is an independent nonprofit organization supported by Deutsche Post World Net. The center is associated with the University of Bonn and offers a stimulating research environment through its international network, workshops and conferences, data service, project support, research visits and doctoral program. IZA engages in (i) original and internationally competitive research in all fields of labor economics, (ii) development of policy concepts, and (iii) dissemination of research results and concepts to the interested public.
\end{abstract}

IZA Discussion Papers often represent preliminary work and are circulated to encourage discussion. Citation of such a paper should account for its provisional character. A revised version may be available directly from the author. 
IZA Discussion Paper No. 3687

September 2008

\section{ABSTRACT \\ Labor Market Policy Evaluation in Equilibrium: Some Lessons of the Job Search and Matching Model ${ }^{*}$}

We analyze the consequences of counseling provided to job seekers in a standard job search and matching model. It turns out that neglecting equilibrium effects induced by counseling can lead to wrong conclusions. In particular, counseling can increase steady state unemployment although counseled job seekers exit unemployment at a higher rate than the non-counseled. Dynamic analysis shows that permanent and transitory policies can have effects of opposite sign on unemployment.

JEL Classification: $\quad \mathrm{J} 64, \mathrm{~J} 68$

Keywords: evaluation, equilibrium effect, labor market policy

Corresponding author:

Pierre Cahuc

CREST-INSEE

Timbre J360

15, Boulevard Gabriel-Péri

92245 Malakoff

France

E-mail: cahuc@ensae.fr 


\section{Introduction}

Most policy evaluations are based on comparing the behavior of participants and non participants in the policy. But the differences in outcome between the treatment group and the control group do estimate the policy mean impact only if the outcomes of the control group are not influenced by the policy, the so-called 'no-interference' (Rubin, 1978) or 'stable unit treatment value' (Angrist, Imbens and Rubin, 1996) assumption. However, the policy may have equilibrium effects that affect the untreated altogether. For instance, Heckman, Lochner and Taber (1998) strikingly illustrate this point in the context of education policies. This issue, which is discussed in a broader perspective in the survey of Meghir (2006), is particularly relevant to the evaluation of labor supply based policies (such as increasing incentives or monitoring the unemployed). First, they generally aim at increasing the overall number of filled jobs, which depends on the interactions between aggregate labor supply and labor demand. Second, these policies may induce displacement effects: treated persons may crowd out the untreated because they compete for the same jobs.

Although they have been long recognized, these questions have received limited attention to date. Davidson and Woodbury (1993) and Calmfors (1994) are early contributions. More recently, Lise, Seitz and Smith (2005) study the equilibrium effects of the Self-Sufficient Project incentive program in Canada. They calibrate an equilibrium model of the labor market so that, when used in partial equilibrium, the model matches the effect of the program estimated by direct comparison of treated and untreated. When equilibrium effects are simulated, the impact of the SSP is far lower. In contrast, Albrecht, van den Berg and Vroman (2005) find, using a calibrated model, equilibrium effects of a Swedish training program to be stronger than implied by direct comparison. The previous results obtained with calibrated models are not fully backed by the empirical evaluations, conducted by Blundell, Costa Dias, Meghir and Van Reenen (2004), of the New Deal for Young People in the U.K. Based on different choice of control groups (unemployed in non pilot areas or ineligible unemployed in treated areas), they find that direct and equilibrium evaluations provide similar results. Using a job search and matching model with skilled and unskilled workers, Van der Linden (2005) shows that micro and equilibrium evaluations are likely to differ widely when job search effort and wages are endogenous. When wages are bargained over, raising the effectiveness of or the access to counseling programs pushes wages upwards and leads to lower search effort among nonparticipants. Induced effects can 
outweigh positive micro effects on low-skilled employment when the response of wages is taken into account.

The aim of our paper is to analyze the impact of counseling in the standard matching model of the labor market (Pissarides, 2000). In our specification, counseled unemployed have a constant comparative advantage in the job search. Using this simple model allows us to analyze the consequences of counseling in a dynamic set-up whereas previous studies are limited to the comparison of steady states. More precisely, we shed some light on three important issues:

(i) What is the true impact of the policy when equilibrium effects are taken into account? The model shows that the true impact of counseling can be very different from what can be concluded when equilibrium effects are neglected even when the treatment group is small. For instance, we find that counseling can increase unemployment when a small proportion of job seekers benefit from counseling, although counseling improves the efficiency of job search. ${ }^{1}$

(ii) What is the impact of the generalization of the policy to a large treatment group? The model shows that there is no simple answer. In particular, the relation between the impact of the policy on unemployment and the size of the treatment group is not monotonous. Strikingly, in our framework, unemployment increases with the size of the treatment group when a small share of job seekers are treated but diminishes with the size of the treatment group when a sufficiently large share of job seekers are counseled.

(iii) What is the dynamic impact of counseling? Many experimentations made to evaluate labor market policies are transitory. Typically, a group of job seekers is selected to benefit from counseling (the treatment group) and the control group will never benefit from counseling. The comparison between the outcomes yields the evaluation of the impact of counseling. Our model allows us to stress that the consequences of permanent and transitory policies can be very different. The difference comes from the reaction of non-counseled job seekers. When the policy is transitory, non-counseled workers do not expect to benefit from counseling in the future. However, when the policy is permanent, the expectation to benefit from counseling in the future induces the non-counseled workers to raise in their reservation wage. In our framework, this phenomenon implies that permanent counseling increases unemployment when a small share of job seekers are counseled whereas counseling always decreases unemployment when it is transi-

\footnotetext{
${ }^{1}$ Our results rely ont the adjustment of wages as in the paper of Van der Linden (2005). However, Van der Linden assumes that wages are collectively bargained over, whereas we assume an individual bargaining framework where counseled and non-counseled workers can get different wages.
} 
tory. Accordingly, it can be misleading to conclude that a truly successful transitory policy will remain successful when it will become permanent.

The paper is organized as follows. The model is presented in section 1. Section 2 is devoted to the impact of counseling in steady state. Transitory dynamics is analyzed in section 3.

\section{The model}

We consider a standard matching model $\grave{a}$ la Pissarides (2000) with a continuum of infinitelylived risk neutral workers. The measure of the continuum is normalized to one. There are two goods: a good produced and consumed, which is the numeraire, and labor. There is a common discount rate $r$, strictly positive. Time is continuous. Workers can be in three different states: (1) employed, (2) unemployed and counseled, (3) unemployed and not counseled. Upon entering unemployment, workers are not counseled. They then enter into counseled status at a rate $\mu>0$ and they keep on receiving counseling until they find a job.

There is an endogenous number of jobs. Each job can be either vacant or filled. Filled jobs produce $y>0$ units of the numeraire good per unit of time, whereas vacant jobs cost $c$ per unit of time. Filled jobs are destroyed with probability $\lambda>0$ per unit of time.

Vacant jobs and unemployed workers (the only job seekers, by assumption) are brought together in pairs through an imperfect matching process. This process is represented by the customary matching function, which relates total contacts per unit of time to the seekers on each side of the market. Let us denote by $u_{n}$ and $u_{c}$ the number of non-counseled and counseled unemployed workers respectively. In our set-up, the only potential effect of counseling is to increase the arrival rate of job offers to the counseled unemployed workers. Let us normalize to one the number of efficiency units of job search per unit of time of each non-counseled unemployed worker. Counseled unemployed workers are assumed to produce a different number of efficiency units of search, denoted by $\delta \geq 1$. In this setting, the number of efficiency units of job search per unit of time amounts to $s=u_{n}+\delta u_{c}$.

The number of employer-worker contacts per unit of time is given by $M(s, v) \geq 0$, where $v \geq 0$ denotes the number of job vacancies and $M$ is the matching function, twice continuously differentiable, increasing, concave in both of its arguments, and linearly homogeneous. Linear homogeneity of the matching function allows us to express the probability per unit of time for a vacant job to meet an unemployed worker as a function of the labor market tightness ratio, 
$\theta=v / s$. A vacant job meets on average $M(s, v) / v=q(\theta)$ unemployed workers per unit of time, with $q^{\prime}(\cdot)<0$. Similarly, the rate at which counseled and non counseled unemployed job seekers can meet jobs is $\delta \theta q(\theta)$ and $\theta q(\theta)$ respectively.

Parameter $\delta$ is estimated by econometricians who evaluate the impact of counseling by comparing the exit rate out of unemployment of counseled workers and the exit rate out of unemployment of non-counseled workers assuming that the arrival rate of job offers to the noncounseled workers is not influenced by counseling. Henceforth, we assume that $\delta$ has been correctly evaluated in this way. The model allows us to analyze the impact of counseling on the non-counseled workers and on labor market equilibrium.

\section{$2.1 \quad$ Job creation}

Let $J_{c}$ and $J_{n}$ be the present-discounted value of expected profit from an occupied job with a counseled worker and a non-counseled worker respectively. Let $V$ denotes the present-discounted value of expected profit from a vacant job. $V$ satisfies

$$
r V=-c+q(\theta)\left[\alpha J_{c}+(1-\alpha) J_{n}-V\right]+\dot{V},
$$

where $\dot{V}$ denotes the time derivative of $V$ and

$$
\alpha=\frac{\delta u_{c}}{\delta u_{c}+u_{n}}
$$

stands for the probability to meet a counseled worker. The free entry condition for the supply of vacant jobs is $V=0$ at any date, implying that

$$
\frac{c}{q(\theta)}=\alpha J_{c}+(1-\alpha) J_{n}
$$

Let us denote by $w_{c}$ and $w_{n}$ the wage of a counseled worker and of a non-counseled worker respectively. The asset value of a job filled with a counseled worker, $J_{c}$, satisfies

$$
r J_{c}=y-w_{c}+\lambda\left(V-J_{c}\right)+\dot{J}_{c} .
$$

Similarly, the asset value of a job filled with a non-counseled worker, $J_{n}$, satisfies

$$
r J_{n}=y-w_{n}+\lambda\left(V-J_{n}\right)+\dot{J}_{n} .
$$

At this stage, it can be shown that the impact of counseling on the arrival rate of job offers to the non-counseled depends on the wages $w_{c}$ and $w_{n}$. 


\subsection{The impact of counseling when wages are exogenous}

Let us assume for a while that wages $w_{c}$ and $w_{n}$ are exogenous. Then, equations (2) and (3), which define the asset value of filled jobs, imply that $J_{c}=\left(y-w_{c}\right) /(r+\lambda)$ and $J_{n}=$ $\left(y-w_{n}\right) /(r+\lambda)$. Substituting these expressions into the free entry condition (1) yields

$$
\frac{c(r+\lambda)}{q(\theta)}=y-\left[\alpha w_{c}+(1-\alpha) w_{n}\right]
$$

It turns out that increases in the share of counseled workers increase the probability $\alpha$ that firms meet counseled workers. Then, equation(4) shows that increases in $\alpha$ reduce the labor market tightness (and then the exit rate out of unemployment of the non-counseled, equal to $\theta q(\theta))$ if the wage of counseled workers is higher than the wage of the non-counseled . In this case, increases in the share of counseled workers raise the proportion of high paid workers. Then, expected profits decrease and firms post less job vacancies. If counseled workers get lower wages than non-counseled workers, we get the opposite result: counseling increases labor market tightness. When wages are identical, labor market tightness is independent of the share of counseled workers. This may be the case when there is a minimum wage that is binding for both counseled and non-counseled workers.

The analysis of the case where wages are exogenous allows us to stress the role played by wage adjustment. In our simple search and matching model where workers are ex-ante identical, counseling may have an impact on labor market tightness, and then on the arrival rate of job offers to the non-counseled workers, if it induces wage differentials between the counseled and the non-counseled.

\subsection{Wage bargaining}

Let us now suppose that wages are bargained over. One needs to define the workers' returns when employed and unemployed in order to derive the outcome of the wage bargaining. The present-discounted value of the expected income stream of, respectively, a counseled and a noncounseled unemployed, is denoted by $U_{c}$ and $U_{n}$. The present-discounted value of the expected income stream of employees who found a job while counseled is denoted by $W_{c}$. The present discounted value of the employees who obtained a job without being counseled is denoted by $W_{n}$. All unemployed workers enjoy some instantaneous return $z$ which includes unemployment benefits and the imputed return of leisure. The non-counseled exit unemployment at rate $\theta q(\theta)$ 
and enter into counseling at rate $\mu$. The counseled exit unemployment at rate $\delta \theta q(\theta)$. Hence $U_{n}, U_{c}, W_{n}$ and $W_{c}$ satisfy

$$
\begin{aligned}
r U_{n} & =z+\mu\left(U_{c}-U_{n}\right)+\theta q(\theta)\left(W_{n}-U_{n}\right)+\dot{U}_{n} \\
r U_{c} & =z+\delta \theta q(\theta)\left(W_{c}-U_{c}\right)+\dot{U}_{c} \\
r W_{n} & =w_{n}+\lambda\left(U_{n}-W_{n}\right)+\dot{W}_{n} \\
r W_{c} & =w_{c}+\lambda\left(U_{n}-W_{c}\right)+\dot{W}_{c} .
\end{aligned}
$$

We assume that the wage bargaining outcome yields a share $\beta$ of the surplus of the job to the worker. The surplus of a job filled by a previously counseled worker is

$$
S_{c}=W_{c}-U_{c}+J_{c}-V
$$

The surplus of a job filled by a worker who did not benefit from counseling is

$$
S_{n}=W_{n}-U_{n}+J_{n}-V
$$

The surplus sharing rule reads

$$
W_{i}-U_{i}=\beta S_{i}, J_{i}-V=(1-\beta) S_{i}, i=c, n .
$$

The outcome of the wage bargaining being defined, it becomes possible to derive the set of equations that defines the value of endogenous variables in equilibrium.

\subsection{Labor market equilibrium}

Using the sharing rule, the definitions of the surpluses and equations (5) through (8) we can write

$$
\begin{aligned}
(r+\lambda) S_{c}-\dot{S}_{c} & =y-z-\theta q(\theta) \delta \beta S_{c}-\lambda \Delta \\
(r+\lambda) S_{n}-\dot{S}_{n} & =y-z-\theta q(\theta) \beta S_{n}-\mu \Delta
\end{aligned}
$$

where $\Delta=W_{c}-W_{n}>0$ satisfies

$$
(r+\mu) \Delta-\dot{\Delta}=\theta q(\theta) \beta\left(\delta S_{c}-S_{n}\right)
$$

Equations (10), (11) and (12) comprise four unknow variables: $S_{c}, S_{n}, \theta$ and $\Delta$. Using the free entry condition (1) together with the sharing rule (9), we obtain a relation between the labor market tightness $\theta$ and the surpluses which involves two more unknown $u_{n}$ and $u_{c}$ :

$$
\frac{c}{q(\theta)(1-\beta)}=\frac{u_{n}}{\delta u_{c}+u_{n}} S_{n}+\frac{\delta u_{c}}{\delta u_{c}+u_{n}} S_{c}
$$


Then, the relations between the labor market tightness and the unemployment rates are derived from the law of motion of $u_{n}$ and $u_{c}$, which read

$$
\begin{aligned}
& \dot{u}_{n}=\lambda\left(1-u_{n}-u_{c}\right)-\mu u_{n}-\theta q(\theta) u_{n} \\
& \dot{u}_{c}=\mu u_{n}-\delta \theta q(\theta) u_{c} .
\end{aligned}
$$

Finally, the system of six equations from (10) to (15) comprises six unknown variables $S_{n}, S_{c}, \theta, \Delta, u_{n}, u_{c}$. Although this system of six equations cannot be simplified into a system with a smaller dimension, it allows us to examine some consequences of counseling on the arrival rate of job offers to the non-counseled. This can be conveniently done by looking at the case where there is a pool of counseled workers and where the entry rate into counseling, $\mu$, equals zero. In that case, the number of counseled workers decreases at rate $\delta \theta q(\theta)$. Equations (10) and (11) show that the surplus of jobs filled with counseled workers is smaller than the surplus of jobs filled with non-counseled workers. ${ }^{2}$ The surplus of job filled with counseled workers is smaller because the reservation wage of counseled workers is higher than the reservation wage of non-counseled workers. Therefore, firms make less profits when they are matched with counseled workers rather than with non-counseled. Hence, as shown by equation (11), the labor market tightness is reduced when more workers are counseled. This induces less job offers to the non-counseled. This phenomenon is amplified when the entry rate into counseling, $\mu$, is positive, because the perspective to be counseled in the future pushes upward the reservation wage of non-counseled workers, which is detrimental to job creation.

\section{Policy evaluation in steady state}

In this section we calibrate the model and we analyze the equilibrium effect of counseling in steady state.

\footnotetext{
${ }^{2}$ When $\delta>1, S_{n}$ is necessarily larger than $S_{c}$. Suppose that this is not the case, so that $S_{c} \geq S_{n}$, then $\delta S_{c}>S_{n}$. From equations (10), (11) and (12), we obtain the folowing expession:

$$
(r+\lambda)\left(S_{c}-S_{n}\right)=-\frac{r+\lambda}{r+\mu} \theta q(\theta) \beta\left(\delta S_{c}-S_{n}\right)
$$

which implies that $S_{c}<S_{n}$, which is incompatible with the assumption that $S_{c} \geq S_{n}$. This enables us to conclude that $S_{c}<S_{n}$.
} 


\subsection{Calibration}

The frequency of the model is monthly. The 3 month interest rate is set to 1.2 percent, which makes the monthly discount factor equal to 0.996 . We need to specify the matching function: $q(\theta)=q_{0} \theta^{\sigma}$ We choose a conservative value for the elasticity $\sigma=0.5$. The bargaining power $\beta$ is set equal to $\sigma$ to ensure that the Hosios condition is fulfilled. We want to reproduce features of the French labour market (means are taken from 2000 to 2007, which correponds to the last business cycle). The instantaneous return of unemployment, $z$, is equal to 60 percent of the productivity $y$, which value is normalized to one. This implies a replacement ratio $(z$ over w) slightly above 60 percent since wages take values around 0.96 in equilibrium. The mean unemployment duration, measured in the Labor Force Survey ("Enquête emploi") between 2004 and 2005, is 1.07 year. The monthly exit rate out of unemployment consistent with this mean unemployment duration is $e_{s s}=7.80$ percent. The overall unemployment rate averaged 9.5 percent over the same time period.

To compute the baseline equilibrium, we assume that there is no counseling so that $\mu=u_{c}=$ 0 and $u_{n}=0.095$. The separation rate is thus $\lambda=0.8$ percent. The cost of posting a vacancy is set to be roughly one third of a period production $c=0.3 y$.

The value of parameter $q_{0}$ of the matching function is determined by the following relation

$$
q_{0}=\frac{c}{y-z}\left(e_{s s}\right)^{\sigma /(1-\sigma)}\left[\left(r+\lambda+\beta e_{s s}\right) \frac{1}{1-\beta}\right]^{1-\sigma} .
$$

\subsection{Policy experiment}

In this subsection, we look at the consequences of the introduction of a counseling policy that improves the efficiency of the search activity of counseled workers. We assume that non-counseled workers produce one unit of search per unit of time, so that their arrival rate of job offers amounts to $\theta q(\theta)$. In line with the estimations of Crepon et al. (2005), we assume that the counseled produce $\delta=1.2$ unit of search per unit of time, so that their arrival rate of job offers is $1.2 \times \theta q(\theta)$.

\subsubsection{The impact of counseling on unemployment}

Figure 1 displays the relation between the unemployment rate and the share of counseled workers in steady state. It is striking that steady state unemployment increases with the share of counseled workers when this share is small, below 10 percent. This result shows that a naive 


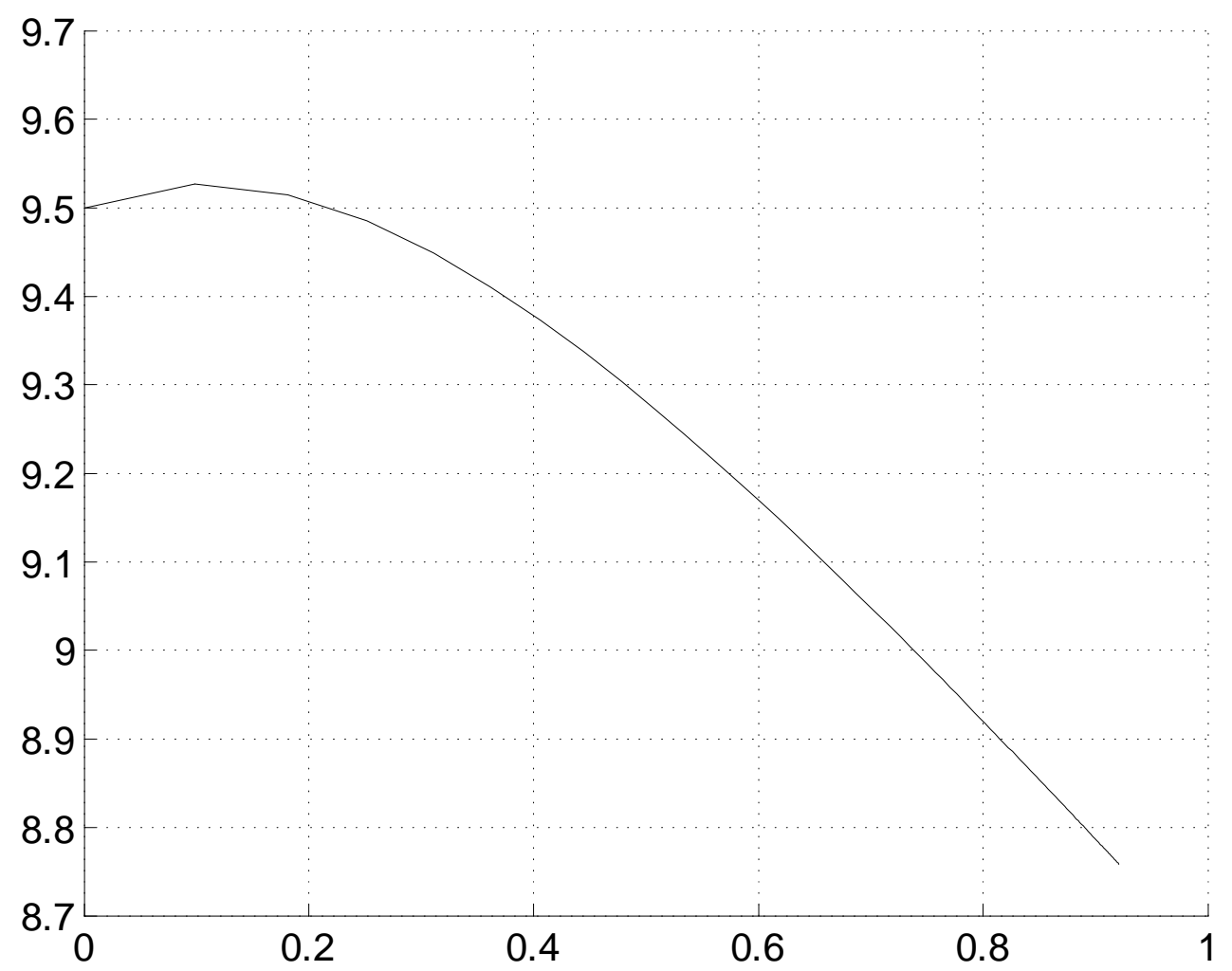

Figure 1: The relation between the unemployment rate (y-axis) and the share of counseled workers ( $x$-axis).

evaluation, relying on a simple comparison of the outcomes of participants and non participants that neglects equilibrium effects, can lead to the wrong conclusion that counseling decreases unemployment, especially when the share of counseled workers is small.

Obviously, the negative impact of counseling on unemployment comes from its effect on the arrival of job offers to the non-counseled. Figure 2 shows that the arrival rate of job offers to the non-counseled decreases with the share of counseled workers. The drop in the baseline arrival rate of job offers, $\theta q(\theta)$, is the result of two effects. First, there is a decrease in profitability due to the new composition of the unemployed population. Because the counseled get higher wages than the non-counseled, ${ }^{3}$ a spread of counseling reduces profitability, this composition effect hinders job creation. Formally, if we differentiate the free entry condition (4), we get:

\footnotetext{
${ }^{3}$ Recall that the counseled get higher wages because counseling enhances their exit rate out of unemployment and then their reservation wage.
} 


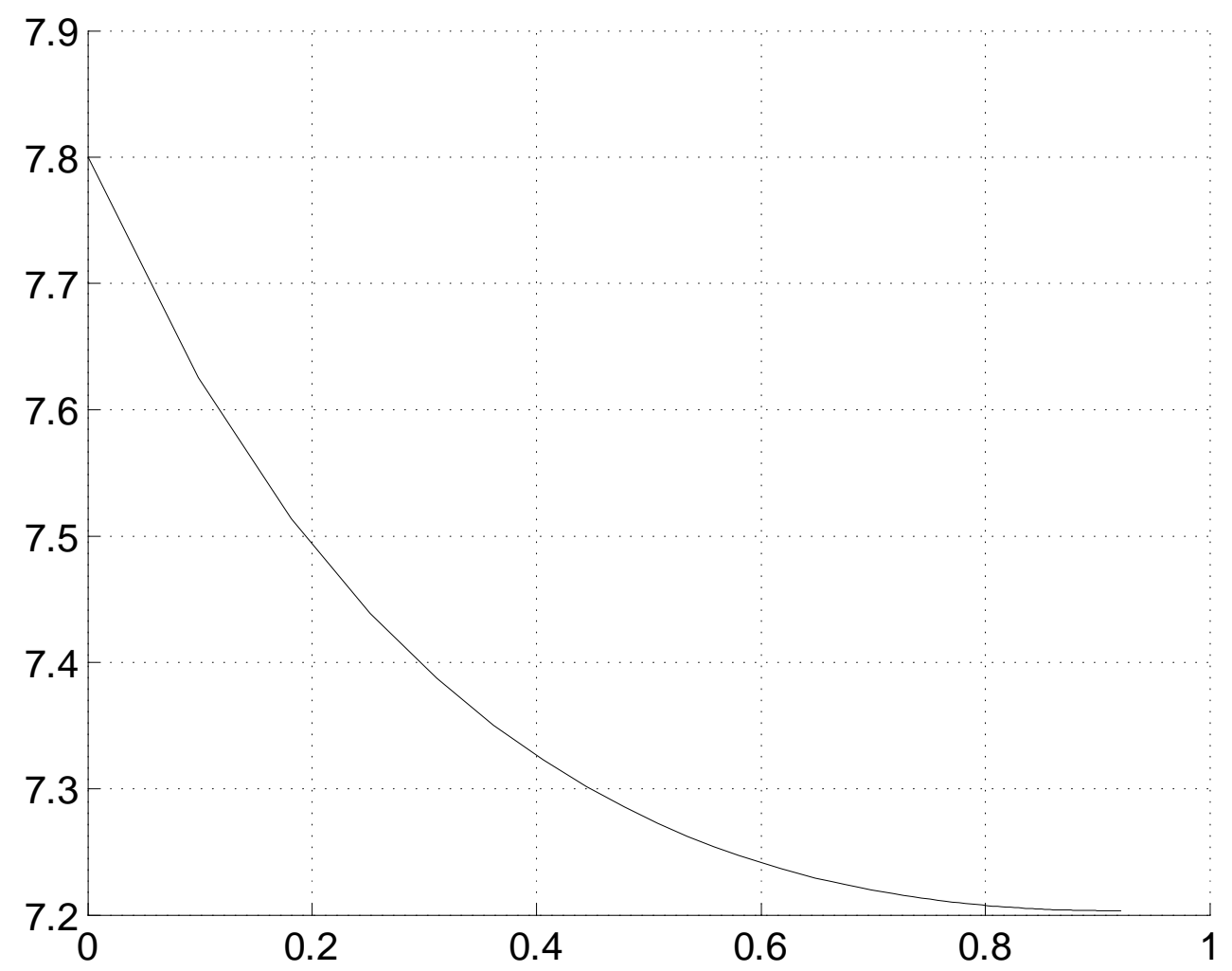

Figure 2: The relation between the arrival rate of job offers to non-counseled workers ( $y$-axis) and the share of counseled workers ( $x$-axis). 


$$
-\frac{c(r+\lambda) q^{\prime}(\theta)}{(q(\theta))^{2}} \frac{\partial \theta}{\partial \mu}=-\frac{\partial \alpha}{\partial \mu}\left(w_{c}-w_{n}\right)-\left[\alpha \frac{\partial w_{c}}{\partial \mu}+(1-\alpha) \frac{\partial w_{n}}{\partial \mu}\right] .
$$

The first term of the right-hand side corresponds to the composition effect. The second effect, which shows up in the second term, comes from the adjustment of wages (see Figure 3). The wage of non-counseled workers is pushed upward by counseling because non-counseled workers anticipate that they may benefit from counseling in the future. In contrast, the wage of counseled workers diminishes with the entry rate into counseling because the opportunity cost of accepting job offers is higher when few job seekers are counselled. More precisely, counseling creates an opportunity cost of accepting job offers: counseled job seekers who find jobs can loose them and will then have to wait a while before benefiting from counseling again. This opportunity cost is higher when the probability to be counseled again, after the accepted job is lost, is lower. Thefore, the opportunity cost to accept a job, and then the negotiated wage, is higher when the entry rate into counseling is smaller.

Finally, the composition and the wage effects result in a negative impact of counseling on the baseline arrival rate of job offers, $\theta q(\theta)$, as shown by Figure 2 .

The decline in the baseline arrival rate of job offers induced by counseling tends to drive the unemployment rate upwards. This effect competes with the direct effect of counseling which makes counseled job seekers leaving unemployment faster. When the share of counseled workers is small, the first effect dominates: the share of non-counseled workers who are adversely affected is large and counseled workers gets very high wages. When the share of counseled workers is large, the second effect dominates: even if counseled workers are numerous, they get lower wages than when they are fewer.

\subsubsection{Welfare analysis}

Our model allows us to yield a welfare analysis. In our context, where workers are risk neutral, instantaneous social welfare is merely equal to the production of employees, $(1-u) y$, plus the production of the unemployed, $u z$, minus the cost of job vacancies, $c v$. Assuming that counseling is provided at zero cost, we find that counseling more unemployed always enhances social welfare, as shown by Figure 4. It is worth noting that social welfare increases with the share of counseled workers even when counseling increases unemployment. We also find that the welfare of noncounseled unemployed, $U_{n}$, increases with the share of counseled workers, although counseling 


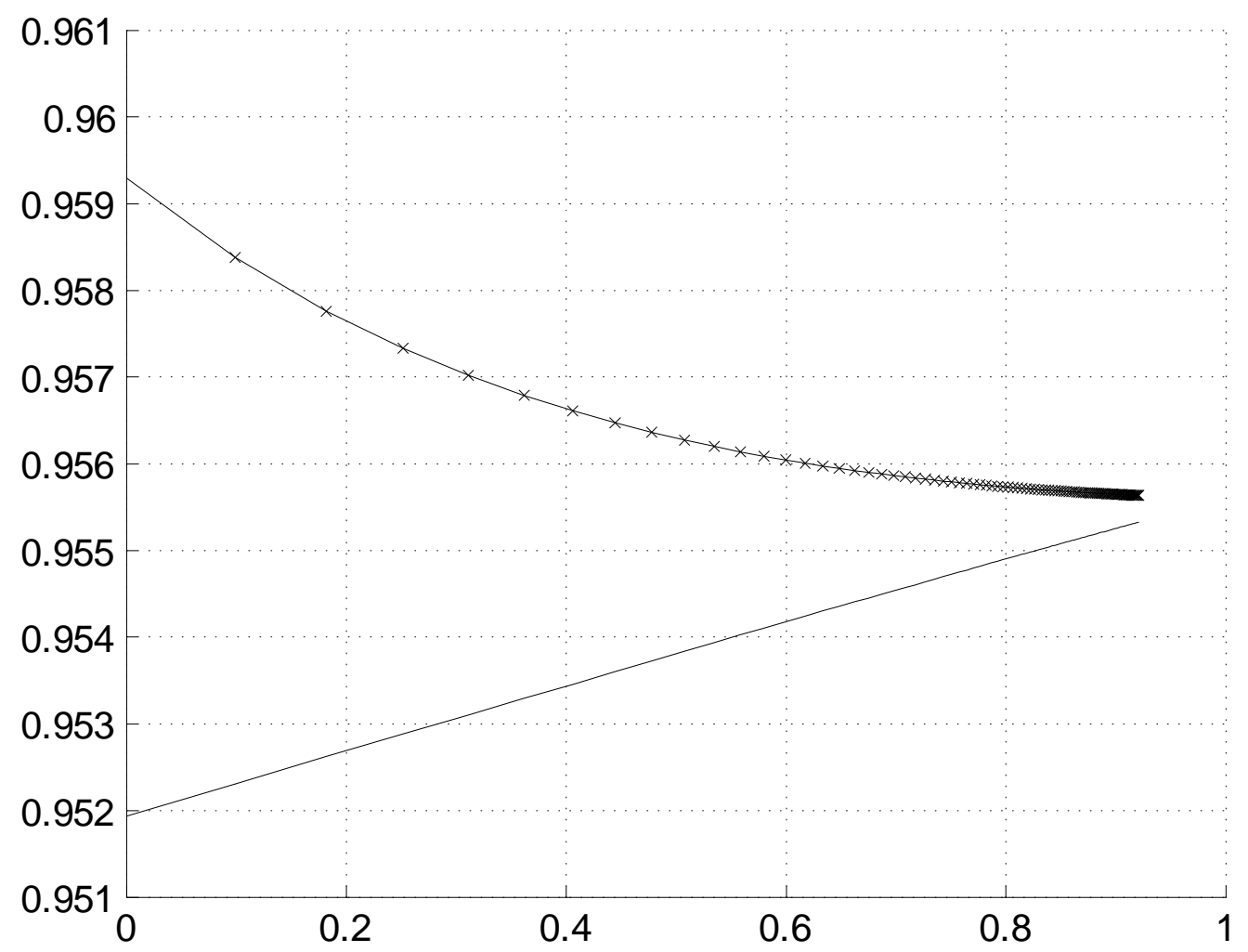

Figure 3: The relation between the wage of counseled workers (broken line) and the wage of non-counseled workers (continuous line) ( $y$-axis) and the share of counseled workers $(x$-axis). 


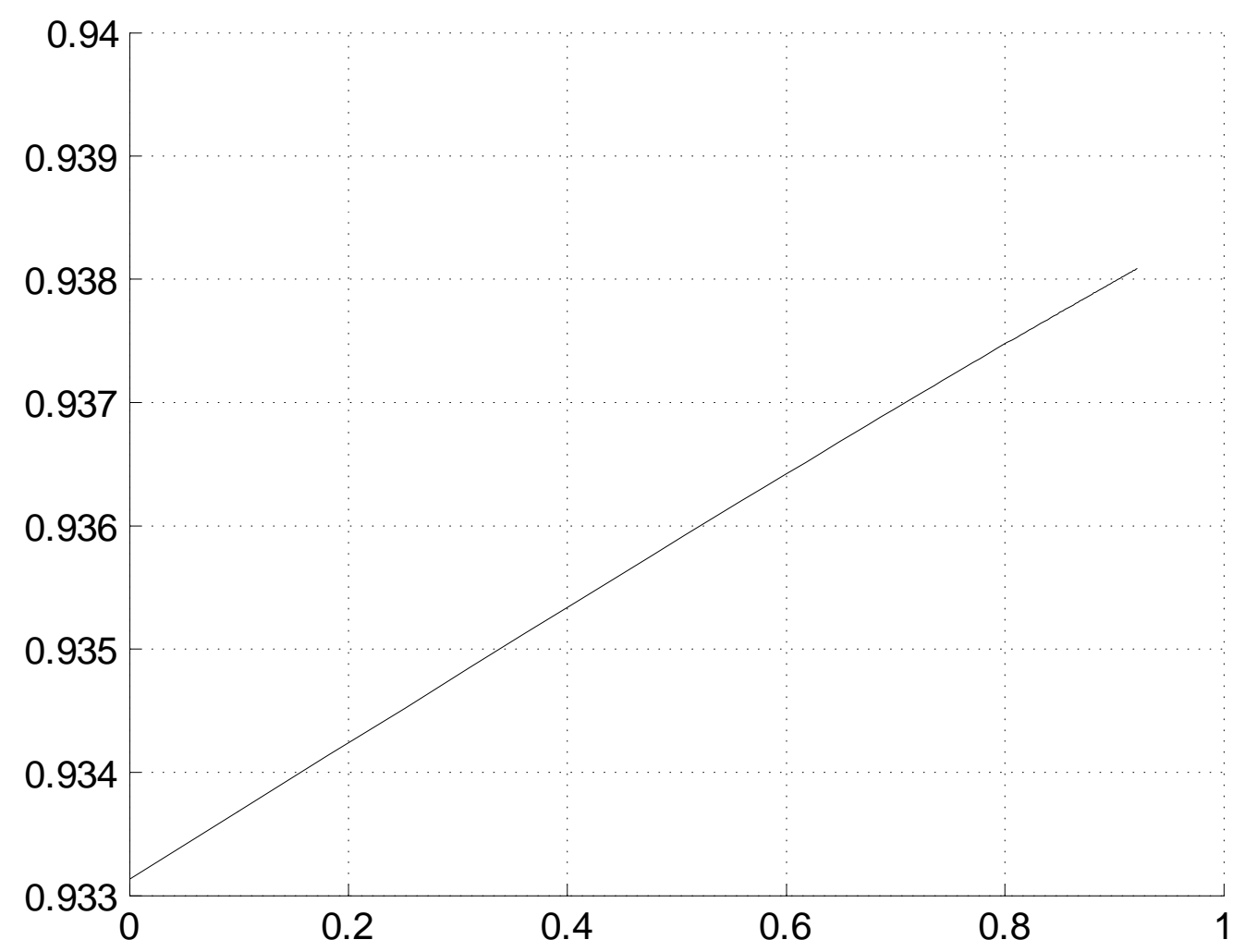

Figure 4: The relation between instantaneous social welfare (y-axis) and the share of counseled workers ( $x$-axis).

reduces the baseline arrival rate of job offers and then their probability to find a job. Actually, non-counseled workers benefit from counseling because the drop in the baseline arrival rate of job offers induced by counseling is compensated by the possibility to be counseled in the future. Counseled unemployed job seekers, like the non-counseled, are always better off in a world with counseling than in a world without. However, their welfare, $U_{c}$, decreases with the share of counseled workers.

\subsubsection{Evaluation errors}

Our model allows us to shed light on the size of the evaluation errors coming from ignoring equilibrium effects. Standard evaluations, relying on a simple comparison of the outcome of the treated and the non treated, can lead to wrong results if the policy induces equilibrium effects which change the baseline arrival rate of job offers $\theta q(\theta)$. The error comes from the choice of wrong counterfactuals when evaluating the impact of the policy: standard evaluations assume 
that the counterfactual arrival rates of job offers to the non treated in the absence of the policy are the same as those observed by the econometrician in the presence of the policy.

In our model, the exit rate out of unemployment of counseled job seekers amounts to $\delta \theta q(\theta)$. Non treated individuals exit unemployment at rate, $\theta q(\theta)$. The effect of the treatment on the treated is usually defined as the ratio between these two exit rates, that is $\delta$. However, this approach yields a naive evaluation of the effects of the treatment to the extent that it does not account for equilibrium effects which may change the value of the arrival rate of job offers to the non counseled job seekers. To account for such effects one needs to know the exit rate out of unemployment in the absence of counseling, that we denote by $\theta_{0} q\left(\theta_{0}\right)$. Then, the effect of the treatment on the treated accounting for equilibrium effects is defined as $\delta \theta q(\theta) / \theta_{0} q\left(\theta_{0}\right)$. The error induced by the ignorance of equilibrium effects, expressed in percentage of the naive evaluation $\delta$, is thus $\left[\theta q(\theta)-\theta_{0} q\left(\theta_{0}\right)\right] / \theta_{0} q\left(\theta_{0}\right)$. Figure 5 shows that the naive evaluation leads to an over estimation of the 'true' effect. The absolute error increases with the share of counseled workers. It is equal to 4 percent when the share of counseled workers amounts to 20 percent and goes up to 9 percent when the share goes to one.

Another error can be made when simulating the consequence of the spread of the policy to all workers. Looking at this error is important to the extent that some policy makers think that policies should first be evaluated at a small scale before being generalized if their evaluations are favorable. This idea is right only if equilibrium effects are properly taken into account. Ignoring such effects can lead to false conclusions, because it is wrong to simulate the impact of the generalization of counseling to all job seekers with the assumption that the arrival of job offers remains unchanged. We can shed light on this type of error by looking at the difference between the true value of the unemployment rate, denoted by $u^{*}$, and the value of the unemployment rate, denoted by $\tilde{u}$, computed when it is assumed that the baseline arrival rate remains unchanged, equal to $\theta_{0} q\left(\theta_{0}\right)$. Figure 6 plots the true unemployment rate, $u^{*}$, (continuous line) and the unemployment rate computed without accounting for equilibrium effects, $\tilde{u}$.

The evaluation error made when equilibrium effects are neglected also biases cost-benefit analysis based on the welfare criterion presented above. As previoulsy assumed, ignoring general equilibrium effects boils down to keeping labor market tightness equal to its value in the absence of counseling. In that case, a naive prediction of the unemployment rates for a given treatment intensity can be computed as in the previous paragraph $\left(\tilde{u}_{n}(\mu), \tilde{u}_{c}(\mu), \tilde{u}(\mu)\right)$. Given 


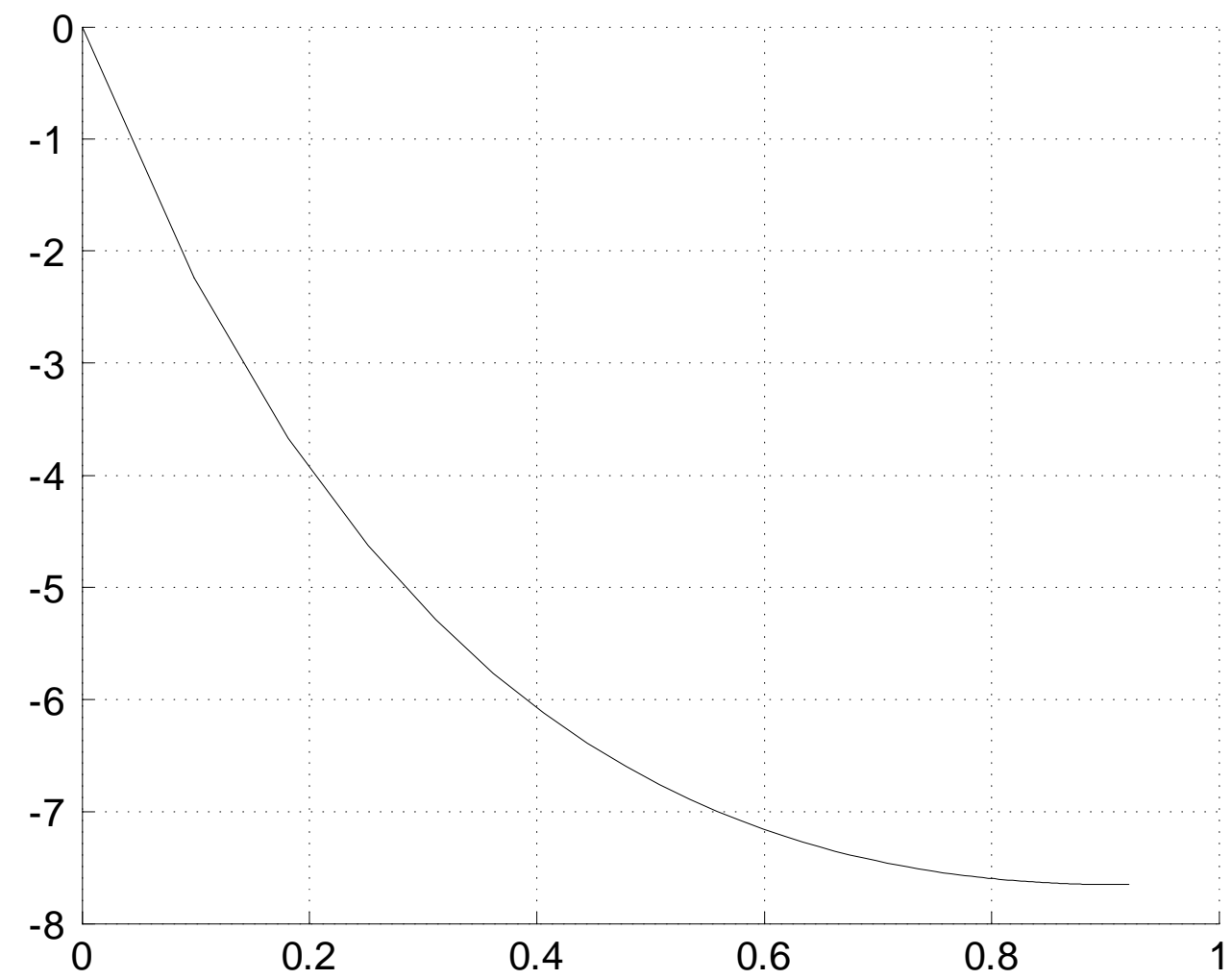

Figure 5: The relation between the error (in percentage of the naive evaluation $\delta$ ) in the evaluation of the effect of counseling on the exit rate out of unemployment of counseled workers (y-axis) and the share of counseled workers ( $x$-axis). 


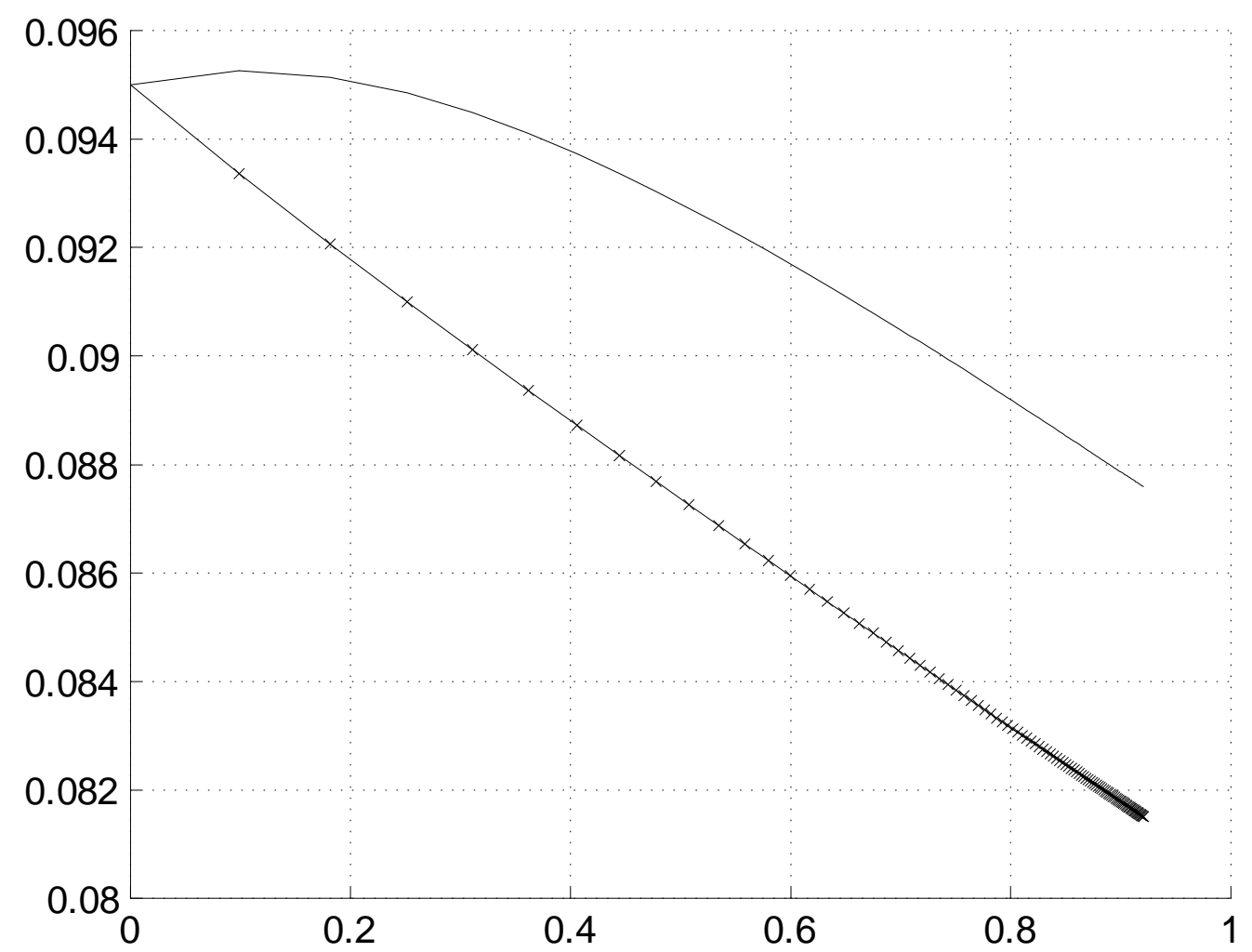

Figure 6: The relation between the unemployment rate (true unemployment rate: continuous line, equilibrium unemployment rate computed without accounting for equilibrium effects: broken line) and the share of counseled workers ( $x$-axis). 


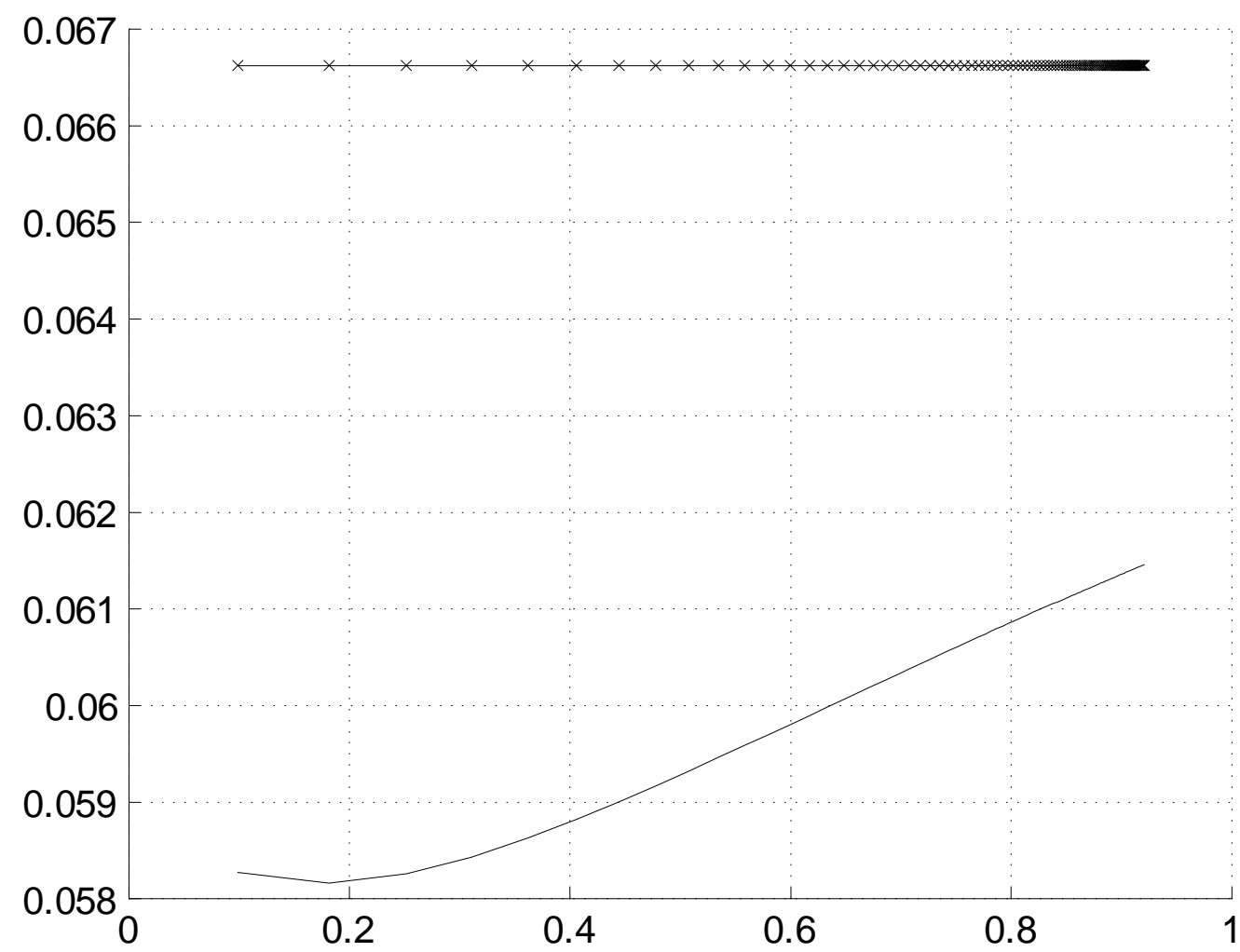

Figure 7: The relation between the maximal profitable counseling cost (true : continuous line, computed without accounting for equilibrium effects: broken line) and the share of counseled workers ( $x$-axis).

these predictions, one can compute the naive net welfare gain from the policy $\Delta_{\mu} \tilde{\omega}$. In the naive cost-benefit analysis, one compares the naive net welfare gain per counseled worker to the unit cost of counseling. ${ }^{4}$ Figure 7 shows that the maximal unit cost of counseling that makes counseling profitable is relatively small, equal to 0.066 (recall that the productivity of employees is normalized to 1). The naive maximal cost above which it is not worth counseling is always higher than the true maximal cost, that accounts for equilibrium effects. The naive evaluation over-estimates the efficiency of counseling because it neglects the negative impact of counseling on the baseline arrival rate of job offers.

\footnotetext{
${ }^{4}$ The unit cost of counseling is defined as the cost per counseled worker during one unit of time.
} 


\section{Policy evaluation and dynamic adjustment}

Up to now, we analyzed the impact of counseling on labor market equilibrium in steady state. It is also important to keep in mind that most labor market policies induce dynamic adjustements that take time. Our model allows us to study the dynamic path of the endogenous variables. We consider three policy experiments that differ by the proportion of people being counseled. In the baseline scenario the entry rate into counseling, $\mu$, is equal to 5 percent. There is also a 'light' scenario, where $\mu$ is equal to 1 percent, and an 'intensive' scenario, with an entry rate into counseling equal to 20 percent. We also consider two versions of these policy experiments. In the first, the policy is permanent: the entry rate into counseling remains constant over time from time $t=0$. In the second, it is transitory: some workers enter into counseling at time $t=0$ only. Then, these workers remain counseled until they find a job and other workers cannot benefit from counseling. ${ }^{5}$ As in the previous section, in all the simulations, the counseled have a comparative advantage which increases their relative probability of finding a job by 20 percent $(\delta=1.2)$.

\subsection{Permanent policy}

In the baseline scenario the entry rate into counseling, $\mu$, is equal to 5 percent, which entails that 36 percent of the unemployed are counseled in steady state. In the 'light' scenario, where $\mu$ equals 1 percent, it turns out that 5.2 percent of the unemployed are counseled in steady state. In the 'intensive' scenario, with an entry rate into counseling equal to 20 percent, 69 percent of the unemployed are counseled in steady state. Figure 8 shows the dynamics of the share of counseled workers for the three cases.

Figure 9 shows that the baseline arrival rate of job offers decreases monotically with time. The baseline arrival rate of job offers adjusts more rapidly to its steady state value when the entry rate into counseling is bigger. However, in all cases considered here, the arrival rate of job offers is very close to its steady state value after one year.

Figure 10 shows that the unemployment rate dynamics is not always monotonic. There is an overshooting of the unemployment rate when the share of counseled job seekers is sufficiently large. This phenomenon is the consequence of the interaction between the positive impact

\footnotetext{
${ }^{5}$ The simulations are made with the software Dynare (http://www.cepremap.cnrs.fr/dynare/) which necessitates to write the model in discrete time. The discrete time version of the model is presented in appendix.
} 


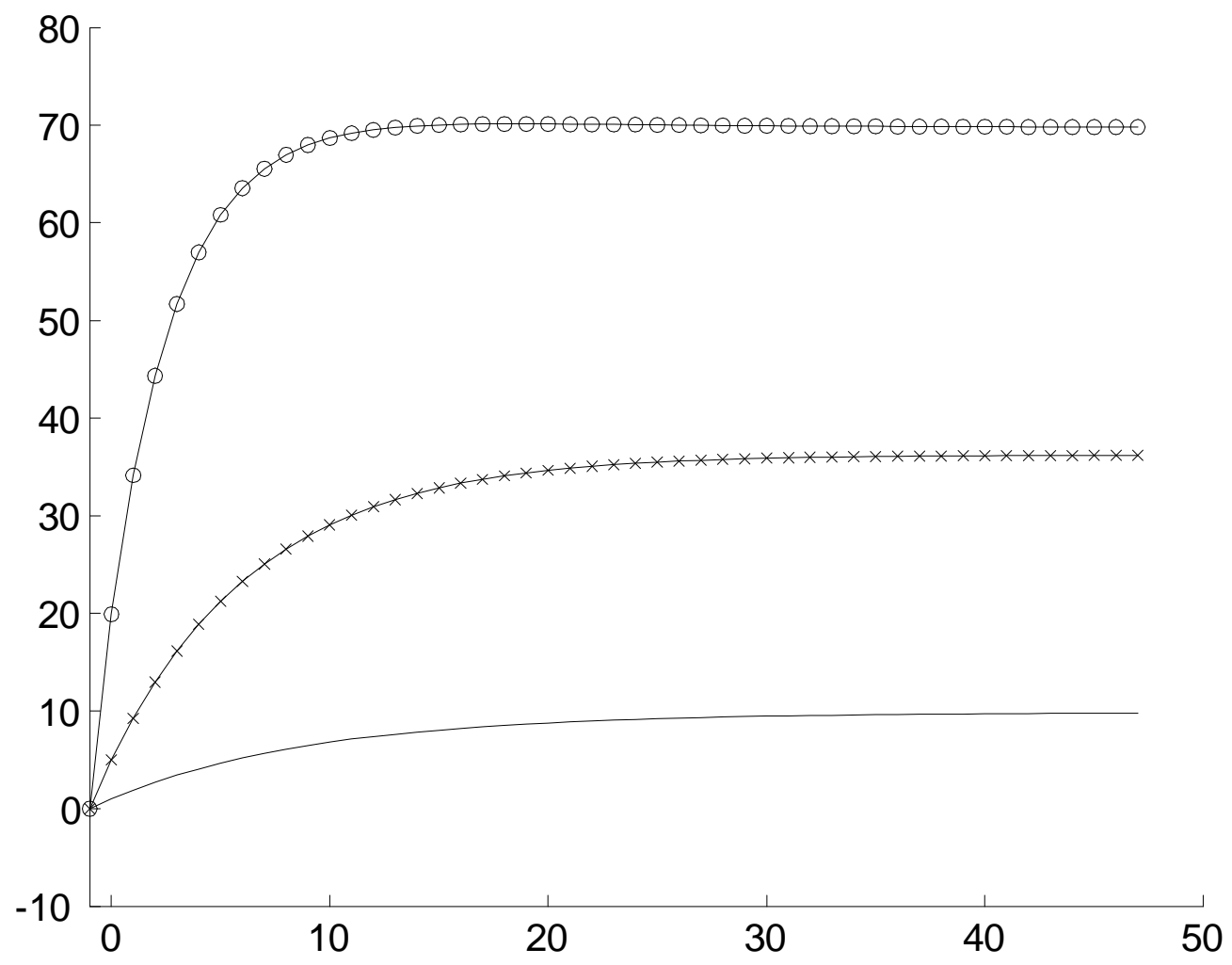

Figure 8: The evolution of the share of counseled workers ( $y$-axis) over time ( $x$-axis, in month) for $\mu=0.01$ (continuous line), $\mu=0.05$ (crosses) and $\mu=0.2$ (circles).

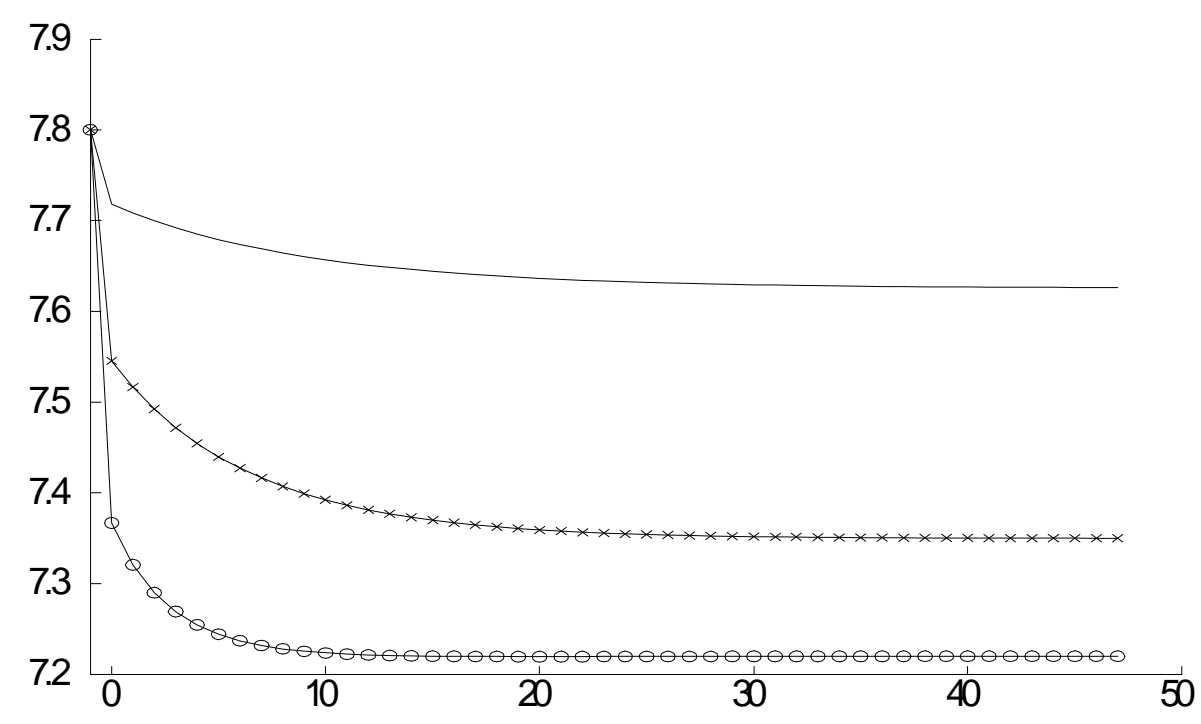

Figure 9: The evolution of the baseline arrival rate of job offers, $\theta q(\theta),(y$-axis) over time ( $x$-axis, in month) for $\mu=0.01$ (continuous line), $\mu=0.05$ (crosses) and $\mu=0.2$ (circles). 
of counseling on the entry rate into employment of counseled job seekers and the equilibrium effects, which reduce the entry rate into employment of the non-counseled. When the entry rate into counseling is large enough, the drop in the baseline arrival rate of job offers, induced by equilibrium effects, dominates at the beginning, which induces an increase in the unemployment

rate. Then, as time elapses, there are more and more counseled workers whose exit rate out of unemployment is relatively high.

Figure 10 leads us to stress that it is important to account for the dynamics of the unemployment rate when evaluating the equilibrium effects of counseling. A priori, it could be possible to estimate the equilibrium effects of counseling by gathering data on similar employment pools in which there are different proportions of counseled individuals. However, this strategy can lead to very different conclusions according to the time horizon at which the evaluation is done. In the baseline scenario, where the entry rate into counseling amounts to 5 percent, the evaluation of the equilibrium effects 6 months after the introduction of the policy leads to the conclusion that they increase significantly unemployment. However, there are no significant effects on the unemployment rate beyond two years.

We also compute the dynamics of the evaluation error $\left[\theta_{t} q\left(\theta_{t}\right)-\theta_{0} q\left(\theta_{0}\right)\right] / \theta_{0} q\left(\theta_{0}\right)$. The true treatment effect on the treated is over estimated by the naive evaluation. As shown by figure 9 , the size of the error increases with time because it takes time to increase the number of counseled workers and then to get sizeable equilibrium effects.

\subsection{Transitory policy}

Now, we look at situations where some workers benefit from counseling at date zero and remain counseled until they find a job. The other job seekers, who do not benefit from counseling at date zero, are never counseled. Figure 12 displays the evolution of the share of counseled workers over time. Figure 13 shows the corresponding evolution of the unemployment rate. It turns out that counseling always decreases the unemployment rate, contrary to the case where the policy is permanent. The difference between the two cases comes from the role of the expectations of noncounseled workers. When the policy is permanent, non-counseled workers anticipate that they will benefit from counseling in the future. Therefore, their reservation wage and then their bargained wage increase (as shown in Figure 3 above). When the policy is transitory, non-counseled job seekers know that they will never benefit from counseling. Therefore, their reservation wage 


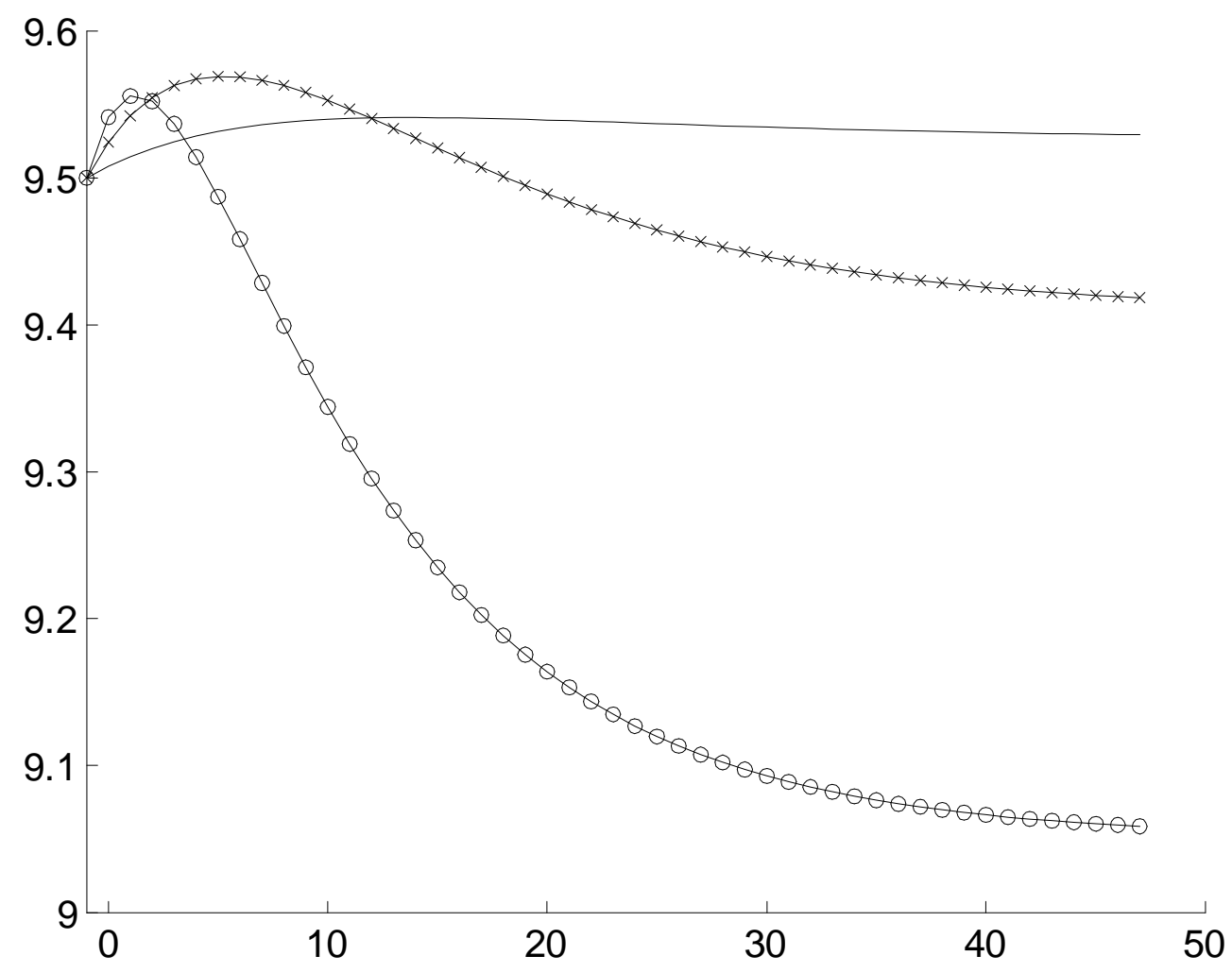

Figure 10: The evolution of the unemployment rate ( $y$-axis) over time ( $x$-axis, in month) for $\mu=0.01$ (continuous line), $\mu=0.05$ (crosses) and $\mu=0.2$ (circles). 


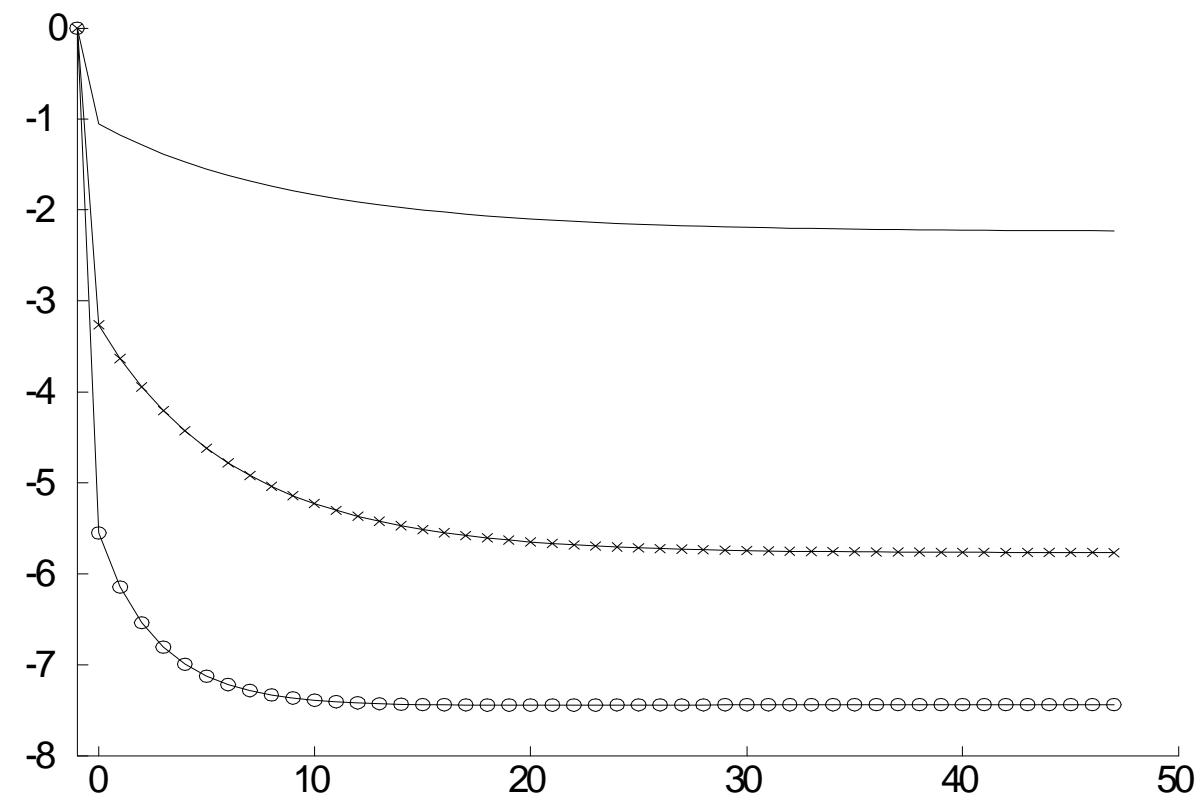

Figure 11: The error (in percentage of the naive evaluation $\delta$ ) in the evaluation of the effect of counseling on the exit rate out of unemployment of counseled workers ( $y$-axis) over time $(x$-axis, in month) for $\mu=0.01$ (continuous line), $\mu=0.05$ (crosses) and $\mu=0.2$ (circles).

does not increase. Actually, their reservation wage decreases because the baseline arrival rate of job offers, $\theta q(\theta)$, drops when some workers are counseled, as shown by Figure 14. Note that there is a spike in the job offer arrival rate at the time of the policy shock. This is due to the assumption made in the discrete time version of the model presented in appendix. At date zero, there is no counseled worker ready to be hired since vacant jobs posted at date $t$ are matched with workers unemployed at date $t-1$ (recall that unemployment is a predetermined variable). Moreover, at date zero, non-counseled job seekers reduce their reservation wage because they anticipate that the baseline arrival rate of job offers is going to decrease in the next future. The combination of this two phenomena increases the value of job vacancies, and then job creation at date zero. At date one, vacant jobs meet counseled job seekers whose reservation wage is higher. This is detrimental to job creation, as shown by Figure 14 .

The comparison of the impact of transitory and permanent policies highlights the role of anticipations. When the policy is permanent, it turns out that a non negligeable share of its impact on the unemployment rate is induced by the reaction of non-counseled job seekers. The raise in their reservation wage, and then in their bargained wage, induced by the expectation to benefit from counseling in the future dampens job creation. This phenomenon implies that 


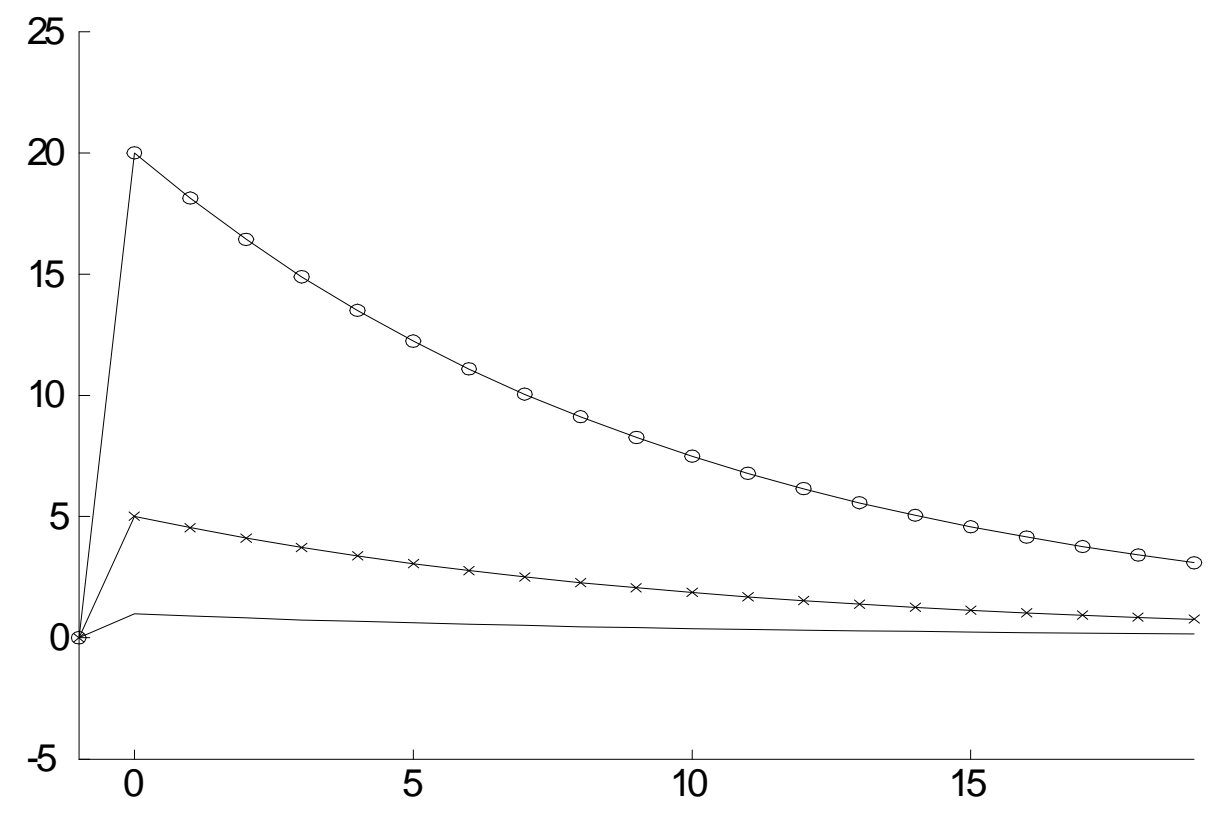

Figure 12: The evolution of the share of counseled workers ( $y$-axis) over time ( $x$-axis, in month) for $\mu=0.01$ (continuous line), $\mu=0.05$ (crosses) and $\mu=0.2$ (circles).

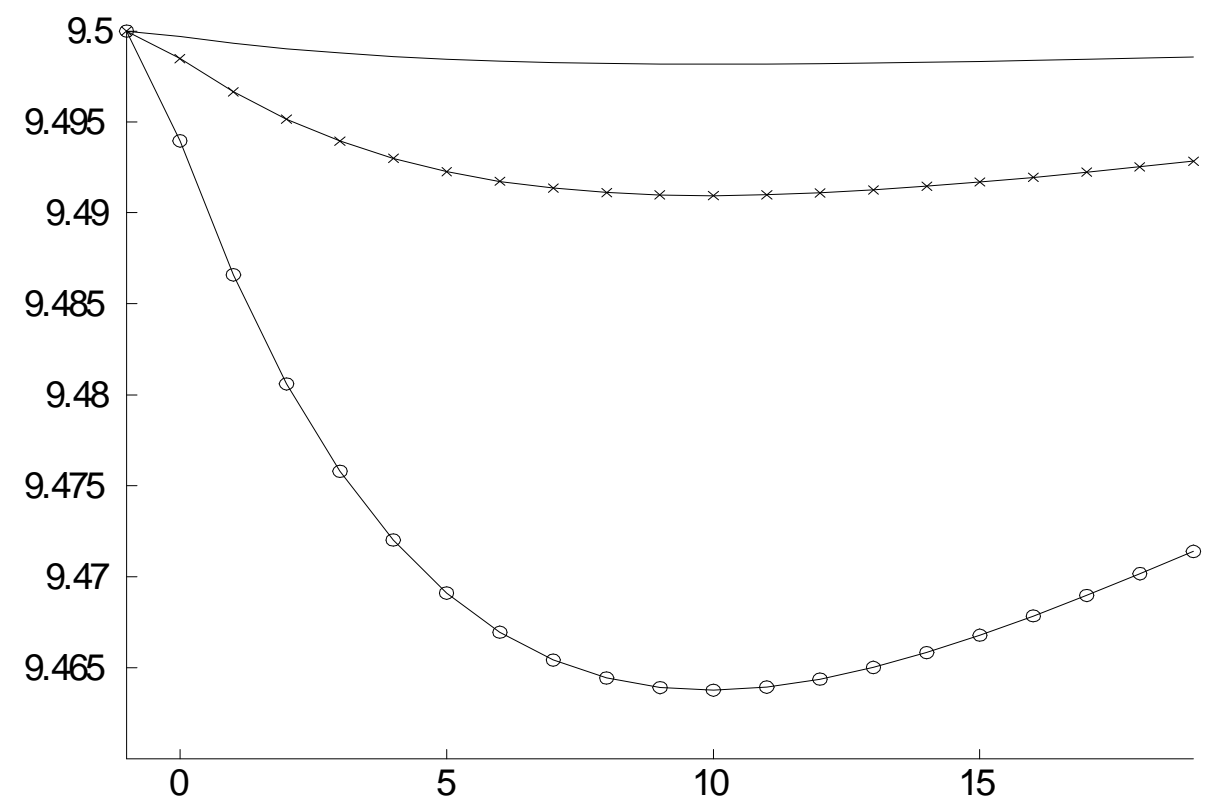

Figure 13: The evolution of the unemployment rate ( $y$-axis) over time ( $x$-axis, in month) for $\mu=0.01$ (continuous line), $\mu=0.05$ (crosses) and $\mu=0.2$ (circles). 


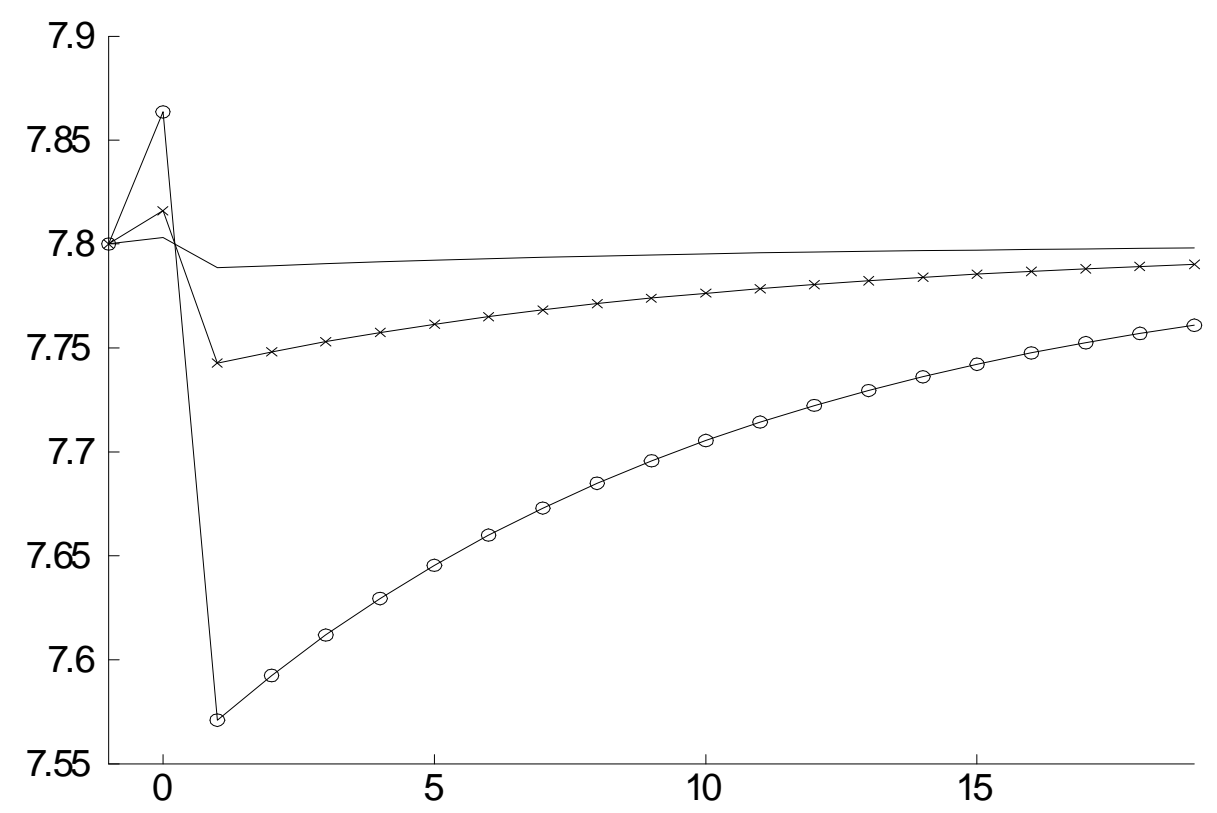

Figure 14: The evolution of the baseline arrival rate of job offers, $\theta q(\theta),(y$-axis) over time ( $x$-axis, in month) for $\mu=0.01$ (continuous line), $\mu=0.05$ (crosses) and $\mu=0.2$ (circles).

permanent counseling increases unemployment when a small share of job seekers are counseled whereas counseling always decreases unemployment when it is transitory. Accordingly, it can be misleading to conclude that a truly successful transitory policy will remain successful when it will become permanent.

\section{Conclusion}

Our paper stresses that it is worth accounting for equilibrium effects to provide a proper evaluation of counseling policies. Neglecting such effects could lead to the conclusion that counseling reduces steady state unemployment although its true effect could be opposite. A striking result obtained in the paper is that this type of error can arise when the size of the treatment group is small. It also turns out that it can be wrong to conclude that a truly successful transitory policy remains successful when it becomes permanent. This result is important to the extent that many policy evaluations rely on the experimentation of policies on a temporary basis. Typically, a policy is evaluated during a transitory period. Then, it is often considered that this evaluation provides relevant information to evaluate the effect of the policy that will be implemented permanently. Our analysis shows that this is not always the case. 


\section{References}

[1] Abbring, J. H. and G.J. van den Berg, 2003, "The non-parametric identification of treatment effects in duration models", Econometrica, 71, 1491-1517.

[2] Albrecht, J., Vroman, S., and van den Berg, G., 2005, "The Knowledge Shift: The Swedish Adult Education Program that Aimed to Eliminate Low Worker Skill Levels." IZA Discussion paper 1503, forthcoming, Review of Economic Dynamics.

[3] Angrist, J., Imbens, G., and Rubin, D., 1996, "Identification of Causal Effects Using Instrumental Variables", Journal of the American Statistical Association, 91, 444-455.

[4] Blundell, R., Costa Dias, M., Meghir, C. and Van Reenen J., 2004, "Evaluating the employment impact of a mandatory job search program" Journal of the European Economic Association, 2, 569-606..

[5] Calmfors, L., 1994, "Active Labor Market Policy and Unemployment - A Framework for the Analysis of Crucial Design Features." OECD Economic Studies. 22(1), 7-47.

[6] Crépon B., Dejemeppe, M. and Gurgand, M., 2005, "Counseling the unemployed: does it lower unemployment duration and recurrence?", IZA Working Paper n¹796

[7] Davidson, C., and Woodbury, S., 1993, "The Displacement Effect of Reemployment Bonus Programs." Journal of Labor Economics, 11, 575-605.

[8] Heckman, J., Lochner, L., and Taber, C., 1998, "General Equilibrium Treatment Effects: A Study of Tuition Policy." American Economic Review, 88(2), 381-386.

[9] Heckman, J. and Smith, J., 1998, "Evaluating theWelfare State" in Steiner Strom (ed.), Econometrics and Economic Theory in the 20th Century: The Ragner Frisch Centennial. Cambridge University Press for Econometric Society Monograph Series, pp. 241-318.

[10] Lise, J., Seitz, S. and Smith, J., 2005, "Equilibrium Policy Experiments and the Evaluation of Social Programs." Unpublished manuscript, Department of Economics Queen's University.

[11] Meghir, C., 2006, Dynamic Models for Policy Evaluation, Institute for Fiscal Studies, working paper $06 / 08$. 
[12] Pissarides, C., 2000, Equilibrium Unemployment Theory. The MIT Press.

[13] Rubin, D., 1978, "Baysian Inference for Causal Effects; the Role of Randomization", The Annals of Statistics, 6, 34-58.

[14] Van der Linden, B., 2005, "Equilibrium Evaluation of Active Labor Market Programme Enhancing Matching Effectiveness.” IZA Working Paper n 1526. 


\section{A Appendix: The model in discrete time}

The aim of this appendix is to present the discrete time version of the continuous time model presented in the text. Unemployment rates are predetermined. During period $t$, matching involve the unemployed populations inherited from the previous period with the job vacancies posted in period $t$. To make clear that unemployment rates are predetermined, we index them by $t-1$. The timing of events within each period is the following, production takes place, firms post vacant jobs, jobs and unemployed workers are matched, jobs are destroyed at rate $\lambda$ and, finally, payments are made. The assumptions about timing allow us to write the system of six equations from (10) to (15) that defines the equilibrium value of $\left(S_{n}, S_{c}, \theta, \Delta, u_{n}, u_{c}\right)$ as follows

$$
\begin{aligned}
u_{n, t} & =\left[1-\mu-\theta_{t} q\left(\theta_{t}\right)\right] u_{n, t-1}+\lambda\left(1-u_{n, t-1}-u_{c, t-1}\right) \\
u_{c, t} & =\left[1-\delta \theta_{t} q\left(\theta_{t}\right)\right] u_{c, t-1}+\mu u_{n, t-1} \\
\text { where } \theta_{t} & =\frac{v_{t}}{\delta u_{c, t-1}+u_{n, t-1}} \\
\frac{c}{q\left(\theta_{t}\right)(1-\beta)} & =\frac{u_{n, t-1}}{\delta u_{c, t-1}+u_{n, t-1}} S_{n, t+1}+\frac{\delta u_{c, t-1}}{\delta u_{c, t-1}+u_{n, t-1}} S_{c, t+1} \\
S_{n, t} & =\frac{1}{1+r}\left[y-z+\left[1-\lambda-\beta \theta_{t} q\left(\theta_{t}\right)\right] S_{n, t+1}-\mu \Delta_{t+1}\right] \\
S_{c, t} & =\frac{1}{1+r}\left[y-z+\left[1-\lambda-\delta \beta \theta_{t} q\left(\theta_{t}\right)\right] S_{c, t+1}-\lambda \Delta_{t+1}\right] \\
\Delta_{t} & =\frac{1}{1+r}\left[\beta \theta_{t} m\left(\theta_{t}\right)\left(\delta S_{c, t+1}-S_{n, t+1}\right)+(1-\mu) \Delta_{t+1}\right]
\end{aligned}
$$

Because agents are risk-neutral per period social welfare can be written as the production net of the cost of vacant jobs. Thus, we define the period welfare as:

$$
\omega_{t}=y\left(1-u_{n, t-1}-u_{c, t-1}\right)+z\left(u_{n, t-1}+u_{c, t-1}\right)-c \theta_{t}\left(u_{n, t-1}+\delta u_{c, t-1}\right) .
$$

The discounted present value of intertemporal welfare, $\Omega_{t}$, writes:

$$
\Omega_{t}=\beta \omega_{t}+\beta \Omega_{t+1}
$$

